Páipéar Taighde Teicniúil

Research Technical Paper

Positive Liquidity Spillovers

from Sovereign Bond-Backed Securities

Peter G. Dunne 


\title{
Positive Liquidity Spillovers from Sovereign Bond-Backed Securities
}

\author{
28 February 2018
}

\begin{abstract}
There are competing arguments about the likely effects of Sovereign Bond-Backed Securitisation on the liquidity of sovereign bond markets. By analysing hedging and diversification opportunities, this paper shows that positive liquidity spillovers would dominate or at least constrain the extent of any negative effects. This relies on dealers using Sovereign Bond-Backed Securities (SBBS) as instruments to hedge inventory risk and it assumes that they diversify their activities widely across euro area sovereign markets. Through a simple arbitrage relation, the existence of low-cost hedging and diversification opportunities limits the divergence of bid-ask spreads between national and SBBS markets. This is demonstrated using estimated SBBS yields (à la Schönbucher (2003)).
\end{abstract}

Keywords: Safe Assets, Securitisation, Dealer Behaviour, Liquidity Bid-Ask Spread JEL: D47, E44, G12, G24, C53, C58

Acknowledgments: I am grateful to Sam Langfield, Marco Pagano, Richard Portes, Philip Lane, Javier Suárez, Kitty Moloney, Patrick Haran, Angelo Ranaldo and members of the ESRB High-Level Task Force on Safe Assets for helpful comments. Views expressed are those of the author and do not necessarily represent the views of the task force. Technical assistance from Paul Huxley at Matlab is also gratefully acknowledged. 


\section{Non-Technical Summary}

This paper forms part of the research-based evidence of the ESRB Task Force on Safe Assets that recently assessed the securitisation proposal of Brunnermeier et al. (2017). Considerable ambiguity exists regarding the likely liquidity effects of this proposal particularly for smaller sovereign markets. A significant fraction of the bonds issued by such sovereigns would be bought by the securitising agent. The amount of an issue held in active portfolios is known to be a determinant of market liquidity.

However, a wider perspective introduces the potential for liquidity spillovers due to hedging and diversification. Specifically, if the markets in sovereign bond-backed securities (SBBS) are liquid, dealing banks can hedge short or long positions with offsetting positions in correlated SBBS. This reduces inventory holding risks to those that are idiosyncratic. By diversifying their market making activities dealers can substantially reduce these idiosyncratic risks.

Hedging effectiveness is assessed in this paper by using estimated SBBS prices derived using the methods of Schönbucher (2003). This produces estimates of risk reduction through hedging using various combinations of the SBBS. It turns out that the senior SBBS alone is usually a good hedge for most individual sovereigns. By analysing a portfolio of such hedged positions it is demonstrated that remaining risks are significantly reduced and are lower than risks associated with investment in German bunds. 


\section{Introduction}

Considerable ambiguity exists regarding the likely liquidity effects of introducing Sovereign Bond-Backed Securities, as proposed by Brunnermeier et al. (2017). The competing forces are (i), a reduced supply of the underlying asset and (ii), improved prospects for the more efficient management of inventory risks. This paper argues that trading costs in country-specific European sovereign bond markets would be constrained by an arbitrage relation as a result of the existence of liquid Sovereign Bond-Backed Securities (SBBS) and this would dominate any negative supply effects. ${ }^{1}$ This outcome relies on sufficient diversification and hedging by dealers in a truly European-wide context. In this sense, and in some other respects to be discussed below, the outcome envisaged is a deeply integrated market in which SBBS become the primary focus for price discovery while trading costs in most national markets shrink to within tight bounds of those in SBBS markets.

Brunnermeier et al. (2016) and Brunnermeier et al. (2017) propose the issuance of sovereign bond-backed securities (SBBS) in the euro area with tranches that would be sequentially exposed to losses arising from defaults on any of the underlying individual sovereign securities. The senior tranche would make up the majority of the securitisation and be extremely low risk. The junior tranches would be more sensitive to early signs of defaults but, at the same time, maintain some of the risk reducing benefits of diversification. In theory, this proposal has potential to induce bond holders to diversify beyond their national sovereign markets and this could substantially weaken the sovereignbank doom-loop that was prevalent during the Sovereign Debt Crisis in Europe. The question remains whether it would work in practice.

1. A wider range of potential effects are considered in the report by the ESRB High-Level Task Force on Safe Assets (2018). 
An apparent drawback of the proposal is that it would leave already small and illiquid sovereign bond markets with reduced free float and this would do further harm to liquidity and raise issuance costs. If orders arrive infrequently in smaller sovereign bond markets - and if orders of a type needed to reduce inventories are inelastic with respect to dealer pricing - then inventory positions will be held for longer and providing continuous liquidity would be costly. It is frequently argued that such costs would rise if the national free float is reduced by absorption into a securitisation.

The analysis below suggests that such a conclusion arises only when national markets are considered in isolation. A wider perspective introduces the potential for liquidity spillovers due to hedging and diversification in market making. Rather than reducing liquidity, the effects of SBBS on sovereign bond markets should have more in common with how opportunities to trade TBAMBS contracts ('to-be-announced' US Agency Mortgage Backed Securities contracts) affect trading costs in Specific-Pools of Mortgage Backed Securities, even those that are not cheapest to deliver. ${ }^{2}$

If SBBS are very liquid they present dealers with instantaneous access to offsetting positions following trades in any given sovereign market and this would established a valid arbitrage relation to constrain trading costs in those markets. SBBS markets (particularly for the senior tranche) are likely to be deeper and more liquid than smaller euro area sovereign bond markets due mainly to the greater amounts of SBBS in issue relative to what is typical for any individual sovereign. But this is also thought likely because SBBS markets (having factor-like properties) would acquire benchmark status. Yuan

2. Gao et al. (2017) describe how, in that market, dealers typically hedge inventory risk in their Specific-Pool exposures with offsetting TBA trades and they show that impediments to hedging can reduce such liquidity. More interestingly, they conclude that the presence of TBA markets has very widespread beneficial effects on liquidity significantly beyond the mortgage pools that are cheapest to deliver. This is also traced to the ability to hedge inventory holding risk. 
(2005) shows that the presence of benchmarks gives rise to liquidity in related markets. ${ }^{3}$

An important difference between the SBBS proposal and the situation discussed in Yuan (2005) is that increased supply of SBBS directly implies a reduction in the supply of individual sovereign bonds outstanding. Yuan assumes, in contrast, that benchmarks enhance the likelihood of issuance of corporate bonds and more issuance improves liquidity. But a positive externality that Yuan's analysis does not take into account is the hedging benefits that dealers can avail of in the presence of liquid benchmarks. It also leaves out post-hedging diversification benefits. These externalities are worthy of further examination.

Although we lack actual evidence of the characteristics of SBBS it is possible to assess their likely behaviour (or, how they would have behaved in the past) through a simulation approach. The present analysis derives SBBS yield estimates using the simulation approach of Schönbucher (2003). This permits an assessment of hedge effectiveness and it shows that dealer inventory positions in most national markets can be, to some extent, hedged by using one or more of the tranches of the sovereign bond-backed securitisation. More importantly, it turns out that, what cannot be hedged is largely idiosyncratic and diversifiable by dealers who are active in many markets. Since inventory risk only requires compensation for its systematic component the liquidity benefits of SBBS are enhanced by diversification.

Hedge effectiveness is assessed by measuring the risk of the optimally-hedged position relative to the unhedged portfolio, as in Bessler et al. (2016).

3. In a related paper, the acquisition of benchmark status in pre-crisis European sovereign bond markets is examined in Dunne et al. (2007). Benchmarks tend to become liquid as they are the location for discovery of the systematic component of the risk premium (in this case, it is envisaged that the different tranches of SBBS would be benchmarks for credit risks within different categories of the market). 
The additional diversification benefits are assessed by assuming that dealers typically have positions in all sovereigns (with both equal weights on individual sovereigns and market-size based weights). A core result from the analysis is that trading costs in SBBS markets would determine limits on the size of trading costs in national sovereign bonds. ${ }^{4}$

The following section outlines the type of hedging behaviour by dealers that is deemed likely when sovereign bond-backed securities exist. The relevant literature is then surveyed. Methodologies used to estimate SBBS yields, to measure time-varying hedge ratios and to assess diversification benefits are then explained. The discussion of results from the application of these methods follows. The conclusion gives some indication of overall liquidity benefits that would flow from the existence of SBBS based on the recent history.

\section{Hedging, Arbitrage and Diversification}

The benefit of hedging with a highly-liquid, contemporaneously correlated, asset is clear-cut in the extreme case of perfect correlation. Let ask and bid prices in the bond market be denoted (a) and (b) and those in the SBBS market be (A) and (B) respectively. Assuming no frictions (i.e., no basis, coordination, execution or timing risks and no variability in market making risks or risk aversion), then arbitrage and competition between dealers should keep the two bid-ask spreads close to each other. ${ }^{5}$ Perfect correlation in the underlying values of the two securities and the assumption of instantaneous

4. Whether these bounds are sufficient to improve on current trading costs is moot. Even if the costs of hedging with SBBS were to exceed current trading costs in national markets, their use in this way would still be relevant in minimising the extent of any deterioration in trading costs due directly to reductions in the free float as a result of the securitisation.

5. This also relies, for simplicity, on the assumption that there is symmetry in the positioning of spreads relative to the underlying value. If not, then the proposition that follows applies on average across many trades. 
availability of trading opportunities in the highly liquid asset, allows us to subtract the common underlying value changes, $\mathbf{V}(\mathbf{t})$, from all bid and ask prices in each period $\mathbf{t}$, leaving $\mathbf{a}^{*}, \mathbf{A}^{*}, \mathbf{b}^{*}$ and $\mathbf{B}^{*}$ as timeless (where starred variables are deviations from the relevant common $\mathbf{V}(\mathbf{t}))$.

A dealer who acquires a long position at a price (b) can immediately sell an equal amount in the SBBS market at price (B). This leaves the position hedged against movements in $\mathbf{V}$ until the bond is sold again at a price (a) and the SBBS is simultaneously bought at (A). Regardless of common movements in $\mathbf{V}$ there is a profit for the dealer of $\mathbf{B}^{*}-\mathbf{b}^{*}+\mathbf{a}^{*} \mathbf{-} \mathbf{A}^{*}$. This profit is trivially increasing in the difference between the spreads s-S. In a competitive market we would expect such differences in spreads to be competed away (excluding any extra costs associated with operating in the more general environment). The spread in the bond market will, in this case, be primarily determined by the required bid-ask spread in the SBBS market.

If there is only a partial correlation between the value of the SBBS and that of the bond then the remaining risk must be managed somehow. In this case, a diversification strategy should be very effective since remaining risks would largely be idiosyncratic. The finding of a substantial reduction in risk due to diversification can be regarded as indirect evidence that SBBS behave like systematic risk factors.

Since only the non-diversifiable component of the unhedged risk will require compensation, the link between the size of the spread in the hedge instrument and that in the asset being hedged is relatively unaffected relative to the case of a perfectly correlated hedge. Standard diversification arithmetic implies that, increasing the extent of diversification from 1 sovereign market to 11 uncorrelated markets with similar-sized risks and activity, would produce more than a $70 \%$ reduction in risk exposure. Hence, if dealers are active in providing liquidity across all European sovereign markets that contribute to 
the securitisation, then any unhedged risks will largely average-out in their trading portfolios. ${ }^{6}$

It is important to draw a distinction between hedging with offsetting positions in an asset possessing highly correlated contemporaneous price movements and the alternative of hedging with a futures contract on the underlying. Futures contracts involve risk premiums that impose direct cost on dealers. There is also a considerable difficulty in correctly matching the expected duration of inventory holding with the expiry time of the associated futures contract. ${ }^{7}$ Matching the size of an inventory position with standardized sizes in the futures market may also be an issue. Hedging with CDS contracts is similar to the use of a correlated asset but this analogy is also incomplete. The CDS premium will only be highly correlated with the credit risk of the underlying security. The disadvantage of the CDS when compared with a factor-like hedge is that it does not hedge systematic interest rate risk. CDS trading also tends to be less liquid than the underlying.

6. It may also be supposed that this benign outcome would be compromised if the SBBS has a difficult-to-forecast correlation with the bond (i.e. if out of sample hedge ratios turn out to be less efficient than they could have been). This is really a type of operational risk and (assuming forecasts are as efficient as possible ex ante) this also gives rise to mostly idiosyncratic and diversifiable risks.

7. Bessler et al. (2016) point out that several futures markets for individual sovereign bonds existed pre-EMU and that the alignment of yields during the years of the Great Moderation was largely responsible for the disappearance of all but the German Bund futures. The Great Financial Crisis and the Sovereign Debt Crisis in Europe ultimately led to the reintroduction of futures on Italian BTPs and French OATs. Futures on Spanish Bonos only reappeared in 2015. Naik and Yadav (2003) examine the use of futures to hedge interest rate risk (undesirable duration) in sovereign bond portfolios of dealers and they find support for the propositions about hedging behaviour by Froot and Stein (1998). 


\section{Microstructure Background, Choosing Hedge Ratios and Assessing Hedge Effectiveness}

Standard models of market making behaviour assume that bid and offer quotes involve a fixed component to cover order processing costs, an inventory management component (e.g., Amihud and Mendelson (1980), Demsetz (1968), Tinic and West (1972), Ho and Stoll (1981), Ho and Stoll (1983) and Stoll (1978)) and an adverse selection component to protect the dealer from losses to more informed traders (e.g., Copeland and Galai (1983), Easley and O'Hara (1987) and Glosten and Milgrom (1985)). In the case of sovereign bonds however, the adverse selection component is regarded as small since nearly all information about underlying value of such bonds is public. ${ }^{8}$

In respect of the inventory imbalance component, Stoll (1978) was one of the first to empirically assess the differential effects of systematic and idiosyncratic risk on dealer pricing. Huang and Stoll (1997) simply assert that the inventory component is mainly related to dealers' portfolio-wide inventory imbalances rather than stock-specific imbalances. They use this fact to separate the inventory component of the spread from the adverse selection component. More recently, Hagströmer et al. (2016) develops a structural model for price formation and liquidity supply explaining how inventory pressure and price discovery is influenced by joint trading of the same or a similar asset in a parallel market. This shows that where hedging opportunities exist trading costs are partially determined by characteristics of the hedge instrument rather than the specific asset.

Naik and Yadav (2003) provides extensive evidence of the use of futures by dealers in the UK Gilts market to hedge duration (they do not discuss credit

8. For example, Naik and Yadav (2003) strongly reject the notion that dealers benefit from their information about orderflow even in the relatively concentrated UK Gilts market. 
risk hedging). They measure risk exposure in two ways; using value-weighted average duration of the whole portfolio of spot and futures bond positions of 15 dealers and alternatively, a value-weighted average of the duration-weighted hedge ratios (where hedge ratios are betas from regressions of returns on individual bonds on the long-gilt futures return). The two measures are very highly correlated (0.92). They show that dealers maintain a short position on average but the spot and futures positions diverge in opposite directions from their means. They conclude that dealers actively use the futures contract to hedge their spot exposures in order to maintain a target level of interest rate exposure.

This hedging behaviour is consistent with theoretical predictions of Amihud and Mendelson (1980). The evidence of partial hedging supports the findings of Stulz (1996) and suggests that what is not hedged is idiosyncratic (only interest rate risk is being hedged in this case as the sample did not involve significant fluctuations in UK sovereign credit risk). The Naik and Yadav study goes on to show that hedging varies with the costs of hedging, volatility of holding returns, risk aversion and capital shortage. They also show that bigger dealing banks hedge less but do not seem to make profits from this - implying that their knowledge of a significant fraction of orderflow does not translate into an economic advantage.

There is a well developed literature dealing with the selection of optimal hedge ratios. Chen et al. (2003) and Lien and Tse (2011) provide extensive reviews of different theoretical approaches to determining optimal hedge ratios. A prominent approach to optimising a hedge position is based on minimising the variance of the returns on the hedged portfolio without regard to optimising the expected returns in some way. This is a particularly suitable approach in the case of hedging to facilitate market making in sovereigns since the objective is to minimise risk for the reward of earning the bid-ask spread (less costs) rather than to improve returns from the underlying investment. 
In the single hedge case the optimal hedge ratio (see Ederington (1979) and Baillie and Myers (1991)) is simply the negative of the slope coefficient in a regression of the asset return on the hedge instrument return. Composite hedging has sometimes been found to be more effective than relying on a single hedge instrument. This has been claimed in the extant literature for the case of hedging positions in corporate bonds using a combination of the relevant sovereign bond and a futures position in the relevant equity, (e.g. Marcus and Ors (1996)), using bonds at particular maturities with futures on a variety of other maturities (e.g. Morgan (2008)) and hedging mortgage backed securities with Treasuries at 2, 5 and 10 years tenors (e.g. Koutmos and Pericli (2000)). Garbade (1999) also provides an interesting application of a two-asset hedge for a bond. This is similar to the case of hedging with both the Senior and Mezzanine (or Junior) SBBS.

Hedge effectiveness is usually assessed by reference to the ratio of some risk measure for the hedged position relative to that of the unhedged position. The optimal hedge ratio and the hedge effectiveness measure typically change through time so hedge effectiveness is normally assessed on a rolling basis across various sub-samples. Engle (2009) applies a pre-crisis model of time varying covariance to the problem of hedge selection during the Great Financial Crisis and shows that this improves on static approaches that were the industry norm at that time. The rolling linear regression results discussed below are therefore unlikely to overstate the achievable hedge effectiveness. Since hedging is inherently about controlling risk in the future, forward-looking estimates of covariances are used in the analysis below to set hedge ratios as though in a real-time context. 


\section{Data and Results}

\subsection{Derivation of $S B B S$ Yields}

Since sovereign bond-backed securities did not exist in the past we rely on estimates of yields on such instruments based on a simulation approach proposed by Schönbucher (2003) - this approach has already been implemented for the case of the SBBS proposal by De Sola Perea et al. (2017) and the ESRB High-Level Task Force on Safe Assets (2018). It is important to state that a motivating principle for the Schönbucher (2003) method is to retain the properties of the underlying relationship between yields and what they imply for default probabilities - including changing correlations and dynamic dependencies. Hence, the estimated SBBS yields in this case are not just some linear combination of the underlying securities (those used as backing for the securitisation). If that were the case, the linear relation would exactly determine the correlations that we rely on for hedge selection. The Schönbucher approach retains the variable probabilities of default in the underlying securities as well as their time-varying interdependencies.

More precisely, the SBBS yield estimation method relies on a simulated defaulttriggering mechanism interacting with an observable market-based proxy for default probability in the underlying securities (in this case the default probability proxy is simply the yield premium in excess of the lowest yield among the sovereigns). The triggering device generates uniformly-distributed triggers on the unit-interval (where all trigger combinations have crosscorrelations of 0.6). Whenever these simulated unit-interval triggers exceed the non-default/survival probability, (1 minus the yield premium), losses are calculated as though defaults have occurred.

Each simulation produces simulated default losses among the underlying bonds. These are summed and allocated sequentially to the SBBS securities according 
to their level of subordination (only spilling-over to a more senior tranche if simulated losses have exceeded the total par value of all subordinates). The sum of the yield premiums of the national bonds, for each simulated day, is then allocated to the yield premiums of SBBS according to their proportional allocation of simulated default losses. Hence the likelihood of triggering a simulated default is determined by the size of yield premiums and by how correlated the triggers are. But risk aversion also has some role in determining the premium. ${ }^{9}$

In this way the probable daily yields on the SBBS components are generated for two different securitisation structures over roughly a 17-year historical period without the need for a structural modelling of the complex dependencies among the underlying sovereigns (e.g. as in Lucas et al. (2017)). This then enables estimation of optimal hedge ratios, hedge effectiveness measures and assessments of the diversification benefits. For reasons of data availability, the simulation is based on yield data for two-, five- and ten-year government bonds of Austria, Belgium, Germany, Spain, Finland, France, Greece, Ireland, Italy, the Netherlands and Portugal, following a weighting scheme based on GDP (averaged over 2006-15). This basket covers approximately $97.5 \%$ of the SBBS volume. As a robustness check, the SBBS yield estimations are re-done using a t-copula instead of the Gaussian copula.

Panels A and B of Figure 1, respectively, depict the time series behaviour of yields on SBBS securities (the derivation of which is discussed above) under two alternative tranching assumptions (70:30 and 70:20:10) while panel $\mathrm{C}$ shows yields of a selection of individual sovereigns. The period of the European sovereign debt crisis is highlighted and extends from November 2009, when

9. The implied risk premium (i.e. yield above the risk-free rate) reflects the risk aversion of the representative market investor on any given day and, hence, may exceed the expected loss anticipated by a risk-neutral investor. This degree of risk aversion enters the simulation and is consequently also reflected consistently in the resulting estimated yields of senior, mezzanine and junior SBBS. 
the Greek government indicated its 2009 deficit projection was being revised upward from $5 \%$ to $12.7 \%$, until just after Mario Draghi's speech making a commitment to 'do whatever it takes' to prevent the break-up of the euro in late July 2012. All of the 10-year yield data used in the hedge selection and assessment analysis discussed in the results section has been converted to price and then daily holding period returns assuming a duration of 9 years.

\subsection{Evidence for Out-Of-Sample Hedge Effectiveness}

The hedge selection and assessment carried out in this paper follows Bessler et al. (2016) who conduct a similar analysis in a European sovereign bond context. In that analysis, hedge ratios and effectiveness were estimated using rolling OLS, constant conditional correlation (CCC), dynamic conditional correlation (DCC-GARCH) and a Bayesian based mixture of models. In the current analysis, hedge ratios and hedge effectiveness (using single or multiple SBBS as hedges) are estimated for each of the 11 individual sovereign bonds. To keep the exposition tractable, and to represent a base case, the results obtained using the rolling linear regressions are presented and discussed in this section. $^{10}$

The optimal hedge for each of the 11 sovereigns (with 10 years to maturity) was estimated on a rolling basis for the case of the following 7 hedge instruments/combinations: \{Senior, Mezzanine, Junior, (Senior and Mezzanine), (Senior and Junior), (Mezzanine and Junior), (Senior, Mezzanine

10. A similar analysis employing dynamic conditional correlation methods, compiling hedge ratios using conditional variances and covariances in line with the relations presented in Appendix A, did not in fact lead to significantly different hedge effectiveness ratios. Also, the combined use of the methods of Gibson et al. (2017) and a stochastic volatility modelling approach designed to address the presence of isolated outliers, due to Chan and Grant (2016), also failed to change the conclusions drawn from the more straightforward application of a rolling linear regression approach. These alternative methods may however lead to improvements when used at higher frequency with regular updating. Extending the analysis to such a frequency is beyond the scope or needs of the present study. 
and Junior) \}. In line with previous literature, the optimal hedge is derived by applying the chosen hedge selection method (e.g., linear regression) over a prior 250 day window and rolling the estimation window forward at regular intervals. The hedge ratio is therefore used in an out-of-sample context for the entire interval between the estimation sub-samples. To keep the exposition tractable, hedge ratio results are presented based on a rolling regression at intervals of 25 days.

Hedge effectiveness for each hedge is assessed by taking the ratio of (i) the hedged and unhedged standard deviations of returns and (ii) the Values-atRisk metrics for the hedged and unhedged positions (i.e. the average of the ratio of the 5\% and 95\% Value-at-Risks for hedged and unhedged cases). These ratios are shown for each of three sub-samples in Tables 1 to 3 and the daily returns on the hedged and unhedged positions, for the case of hedging with just the senior and for the case of hedging with a mixture of the senior and mezzanine, are shown in Figures 2 to $4 .{ }^{11}$

The visual evidence indicates that hedging is generally effective in the pre-SDC period in reducing the volatility of returns (with some isolated exceptions). Hedging is not effective for high-risk sovereigns during the height of the SDC but effectiveness returns to some extent during the recovery. In general the combined hedge works better than the single hedge in the crises and recovery periods. Figure 2 reveals that hedging is quite consistently effective for three countries (DE, FR and NL). In these cases the composite hedge seems to eliminate the occasional blips present in the single hedge case. Similarly consistent levels of effectiveness are found for AT and FI (not displayed).

Figure 3 shows the cases of (BE, ES and IT). This clearly reveals how idiosyncratic the experiences of each of the high-risk periphery countries was

11. The cases of Austria (AT) and Finland (FI) are not shown above but are quite similar to the case of NL. 
during the crisis (making them difficult to hedge using SBBS). It is interesting that the composite hedge (senior and mezzanine) works better than the single hedge during the crisis and recovery (apart from one particular day). This tends to improve further with the inclusion of the junior SBBS as a hedge instrument (this more general case is not displayed in the figure but can be seen from the tabulated results discussed below).

Figure 4 shows the more volatile cases of (GR, IE and PT). Here again there is evidence of hedge ineffectiveness during the crisis with improvement only obvious during the recovery for IE and PT. Again, the composite hedge is better than the single hedge during the recovery for these countries and is particularly good in protecting from the more extreme movements. Although hedging is least effective in reducing risk in the case of the smaller markets, their idiosyncratic risk is more amenable to control using diversification strategies (this is addressed below).

The tabulations of relative risks can provide some more depth to the graphical analysis. The pre-Sovereign Debt Crisis period comparisons are in Table 1 and this is clearly a period where hedge effectiveness is high for all countries (at least for some of the 7 hedges). The best hedges for each sovereign are highlighted in colour for the cases of 1-SBBS and 2-SBBS as hedges. In the case of the single hedge it is the senior-SBBS that gives the best protection (the hedged/unhedged risk ratio for the best single hedges - based on standard deviation of daily returns - ranges from 0.21 for DE to 0.64 for GR). In almost all cases the 2-SBBS hedge provides some marginal improvement in hedge effectiveness over the 1-SBBS hedge case (all ratios below 0.50). In many cases the 3-SBBS hedge is best overall but this may not always be worthwhile from a cost and operational perspective.

Table 2 shows summary statistics for hedged/unhedged relative risks during the sovereign debt crisis. For the 1-SBBS hedge only DE remains well hedged 
using the senior SBBS (0.32). Roughly half of the risk is avoided by singleSBBS hedging for the case of FI and NL while the remaining sovereigns are clearly not amenable to single-SBBS hedging in this crisis period. Moving to 2-SBBS or 3-SBBS hedging generally gives rise to some small but significant risk reduction for most sovereigns relative to the single-SBBS case. Table 3 covers the recovery period (from Mario Draghi's London Speech until the end of the last quarter of 2016). By use of composite hedging it is usually possible to reduce risks by half or more. The exceptions remain GR and PT.

\subsection{Post-Hedging Diversification of Risks}

Once risks have been hedged there is potential for dealers to diversify remaining risks by operating simultaneously across many of the sovereign markets. At each moment of a trading day (and at the end of each day) it is likely that a dealer will have a portfolio of outstanding positions in many markets. The individual net hedged-positions are likely to be much smaller than unhedged positions (e.g. if the hedge-ratio is close to 1 then the individual net hedged-positions will be minor). These net positions in individual sovereigns could be subject to further netting (i.e., if some are net-long and others are net-short). Risk reduction from this additional type of netting is not included in the following analysis (i.e. portfolios will be restricted to be hedged long-positions in the components). This most probably implies a significant underestimate of the risk reduction that could be achieved by diversification.

The upper panel of Figure 5 compares returns on a cross-country portfolio of hedged and unhedged positions for the pre-SDC period. In this case it is assumed that the portfolio results from an equal weighting on the underlying sovereigns. Firstly, it is clear that the portfolio of hedged positions has a much smaller dispersion than the portfolio of unhedged components. Despite the equal weighting of components and the equal capital exposure assumption, 
diversification reduces risks much more for the portfolio with hedged positions and this is due to the fact that there are mostly idiosyncratic risks surviving in the hedged case while the unhedged case will involve considerable systematic risk.

The lower panel of Figure 5 concerns the more volatile conditions of the SDC and the recovery. In this case there is not much benefit from the hedging because most risk is actually idiosyncratic. This means that diversification is equally effective in the case of the unhedged portfolio. In general the risks are much lower than risks for typical single sovereigns during this period. Hedging starts to matter again during the recovery.

A related comparison is that of the dispersion of returns on the safest single sovereign asset and those of the portfolio of hedged sovereign positions (the German 10 year Bund returns are used for this discussion but these are almost indistinguishable from the returns on the similarly safe senior SBBS). Figure 6 displays these returns through time for the pre-SDC period and the sample from the start of the SDC through to the more recent recovery. It is very obvious that the portfolio of hedged sovereigns has an extremely low risk level when compared with the most safe sovereign (especially in the pre-SDC period). This demonstrates the effectiveness of diversification in reducing risks when risks are idiosyncratic and not too extreme. The effectiveness of diversification is compromised from the start of the SDC but there is still some significant reduction in risk for the majority of the sample (with a small number of extreme outliers). For normal risk levels diversification is a strong driver of risk reduction.

Table 4 broadens the analysis of the relative risks following diversification to the case of a size-weighted portfolio and to other maturities. These results 
pertain to the case where the senior SBBS is used as the hedge instrument. ${ }^{12}$ The tabulated results for the 10 year bonds confirm what was clear from the graphical analysis. In the pre-SDC period most risk ratios are around 0.3 indicating significant reduction in risk due to a combination of diversification and hedging relative to diversification on its own. It also confirms that risks after hedging and diversifying are less than a third of those faced by investing in the lowest risk sovereign (close to what is the maximum reduction possible when investing the same capital in 11 assets with similar idiosyncratic risks rather than 1). In this period (for the 10 year term) there is little difference between the equal and size-weighted portfolio results.

For the 10 year term there is little benefit from hedging before diversifying during the Sovereign Debt Crisis period (the ratio of the risks on portfolio returns when components are hedged is roughly equal to the risks with unhedged components which is tantamount to saying that almost all risks are idiosyncratic). Diversification reduces risks again in the Recovery period and this is particularly true for the size-weighted portfolio. Risk is relatively high for the equally-weighted portfolio compared with the German bond for the Sovereign Debt Crisis period but otherwise risk is similar to or less than that of the German for the SDC and Recovery respectively.

In the case of the 5 year term, risks are reduced by around $45 \%$ in the preSDC period via a combination of hedging and diversification relative to just diversification (the extra risk reduction achieved in the 2 year case is similar to that of the 10 year). As with the 10 year case, hedging does not achieve significant extra benefit in terms of risk reduction for the 5 year bonds during the SDC (and this is also true of the 2 year term-to-maturity). There is about a ten percentage point difference in the risk reduction due to hedging during

12. The weights used in the analysis are related to the size of the individual sovereign float relative to that of the total of 11 sovereigns in the euro area market (weights are provided in the notes for Table 4). 
the Recovery between the 2 and 5 year terms with more reduction achieved in the 5 year category. As for comparison with the German sovereign, an equally weighted portfolio of sovereigns has 1.52 and 3.52 times the volatility of the German bond (for the 5 and 2-year case respectively) during the SDC (the associated relative $\mathrm{VaR}$ measures and the size-weighted comparisons show a smaller difference in these risks but in all cases risk are greater than holding just the German). The Recovery period does not appear to be as positive for risk reduction through the combination of hedging and diversification for the 2 year term. However, portfolio risks remain low and are not much greater than those of the lowest risk sovereign.

\section{Summary of Results for Extensions}

The possibility that similar hedge (and diversification) strategies might be just as good as SBBS has been ignored. The effectiveness of hedging using futures (in particular, German Bund and Italian BTP bond futures) is addressed in Appendix B. The principal finding here is that the senior SBBS is a much better hedge than Bund futures (even ignoring the fact that hedging with futures involves other additional costs and basis risks). Additionally, where SBBS are ineffective as hedges for smaller sovereigns (such as IE and PT) the futures are also very ineffective so there is no clear superiority in terms of hedge effectiveness using futures rather than SBBS.

Appendix B also contains details of the generalisation of the analysis to other maturities and to the case where SBBS yields are generated using a multivariate t-copula to trigger defaults. The outcome of these extensions is straightforward to summarise. Firstly, extending to shorter maturities leads to a general reduction in hedge effectiveness on average in the pre-crisis period and a less pervasive reduction in hedge effectiveness for the 2-year maturity in the recovery period. Ultimately, this does not impact greatly on the risks 
that remain after diversification. Secondly, since the t-copula produces a higher incidence of extreme losses that more often spillover to mezzanine and senior tranches, the yield movements that result are less correlated with those of the German sovereign bonds than is the case with the Gaussian copula. The senior tranche therefore becomes less effective as a hedge for German bonds. Otherwise the changes in hedge effectiveness due to use of the t-copula are insignificant.

\section{Conclusion}

This paper assesses how the existence of sovereign bond-backed securities affects dealer intermediation in individual euro area sovereigns. An arbitrage relation is used to demonstrate that the hedging of inventory risks with SBBS eliminates most systematic inventory holding risks. Furthermore, it is asserted that diversification of intermediation activities across countries, in combination with hedging, then produces further reductions in exposures. These assertions are tested using estimated SBBS yields and the findings are generally positive. Even if one assumes a similar capital exposure under hedging and not-hedging, there is still a marked reduction in risks through hedging and diversification. Overall, assuming regulation does not excessively penalise netting of inventory positions in different sovereign and SBBS, and if SBBS are sufficiently liquid, a significant improvement in trading costs across all European sovereign debt markets seems plausible.

Risk reduction through diversification (after hedging) was assessed using equalweighted and size-weighted portfolios of long positions in the bonds from the underlying sovereigns. This could be misleading since it is quite likely that actual inventories would be some mixture of long and short positions. This simplification will tend to underestimate the risk-reducing benefits of diversification. Since holding period investment returns in sovereign markets 
are predominantly positively correlated (except when there is a pronounced flight to safety), a combination of long and short positions will lead to more netting of valuation changes and this will most likely reduce risk relative to what is reported for the present analysis. This represent a fruitful avenue for future investigation.

A further useful extension of the above analysis would be to assess whether there are liquidity spillovers among the SBBS tranches. In fact, these spillovers have already been identified in terms of the incremental hedge effectiveness that was achieved when portfolios that included all three SBBS were analysed. But in the developmental phase of the SBBS market, liquidity spillovers between the SBBS themselves could be important for liquidity of the junior tranche which will have the smallest issuance volume among the three. It seems likely that the senior SBBS would be helpful to dealers in providing quotes in the mezzanine market (purely via hedging). A spillover from the mezzanine to the junior is then possible. Preliminary analysis of the correlations between the tranches under most circumstances suggests that these hedging avenues for liquidity spillovers would be positive. Of course, in crisis circumstances flight to safety could disrupt correlations more dramatically than can be anticipated by dealers and this would undermine the reliability of risk reduction strategies based purely on hedging one SBBS with another. This is worthy of further investigation.

It is important to acknowledge that providing liquidity by relying on a parallel market for hedging requires adequate funding liquidity, regulation that permits the netting of inventory positions and broad-based diversification by dealers. Any systemic contraction in availability of funding liquidity is likely to disproportionately affect liquidity in markets that depend on hedging (see Brunnermeier and Pedersen (2009)). It is important therefore that dealers 
have adequate capital to withstand relatively large shocks. ${ }^{13}$ Regulation that prevents netting of positions of intermediaries would constrain positive liquidity spillover effects. Similarly, large changes in correlations can magnify risks during a crisis so trading systems need to be dynamically flexible and capable of managing such complexity. This may increase operational costs.

One important policy implication of the analysis above is that primary dealers will seek to have a presence in more markets. This follows from the fact that much of the risk at local level cannot be hedged using SBBS but is easily diversified. Dealers with, on average, a more diversified portfolio will face lower risks and will be able to out-price non-diversified dealers. Most markets in Europe have a majority of dealers with diversified market making activities but some additional diversification is likely to occur. There is obviously a trade-off here between specialisation, which helps to make price discovery more efficient, and diversification for risk management purposes.

13. It has been shown by Baranova et al. (2017) that recent tightening of capital and leverage requirements of financial intermediaries has damaged liquidity provision during calm markets conditions but it has helped to protect liquidity during crises circumstances. Getting the balance right is therefore crucial. 


\section{References}

Amihud, Y. and H. Mendelson (1980). Dealership market: Market making with inventory. Journal of Financial Economics 8, 31-53.

Baillie, R. T. and R. J. Myers (1991). Bivariate GARCH estimation of the optimal commodity futures hedge. Journal of Applied Econometrics 6(2), 109-124.

Baranova, Y., Z. Liu, and T. Shakir (2017). Dealer intermediation, market liquidity and the impact of regulatory reform. Bank of England Staff Working Paper 665.

Bessler, W., A. Leonhardt, and D. Wolff (2016). Analyzing hedging strategies for fixed income portfolios: A bayesian approach for model selection. International Review of Financial Analysis, Forthcoming. Available at $S S R N$.

Brunnermeier, M., S. Langfield, M. Pagano, R. Reis, S. Van Nieuwerburgh, and D. Vayanos (2016). The sovereign-bank diabolic loop and ESBies. American Economic Review Papers and Proceedings 106(5), 508-512.

Brunnermeier, M. K., S. Langfield, M. Pagano, R. Reis, S. van Nieuwerburgh, and D. Vayanos (2017). ESBies: Safety in the tranches. Economic Policy 32(90), 175-219.

Brunnermeier, M. K. and L. H. Pedersen (2009). Market liquidity and funding liquidity. The Review of Financial Studies 22(6), 2201-2238.

Chan, J. C. and A. L. Grant (2016). Modeling energy price dynamics: Garch versus stochastic volatility. Energy Economics 54(Supplement C), 182 - 189.

Chen, S. S., C. Lee, and K. Shrestha (2003). Futures hedge ratios: A review. Quarterly Review of Economics and Finance. 43, 433-465. 
Copeland, T. C. and D. Galai (1983). Information effects on the bid-ask spread. Journal of Finance 38, 1457-1469.

De Sola Perea, M., P. G. Dunne, M. Puhl, and T. Reininger (2017). Sovereign bond backed securities: A VAR-for-VaR \& Marginal Expected Shortfall assessment. mimeo.

Demsetz, H. (1968). The cost of transacting. Quarterly Journal of Economics 82(1), 33-53.

Dunne, P. G., M. J. Moore, and R. Portes (2007). Benchmark status in fixedincome asset markets. Journal of Business, Finance \& Accounting 34(9-10), 1615-1634.

Easley, D. and M. O'Hara (1987). Price, trade size, and information in securities markets. Journal of Financial Economics 19, 69-90.

Ederington, L. (1979). The hedging performance of the new futures markets. Journal of Finance 34, 157-170.

Engle, R. (2009). Anticipating Correlations. New Jersey: Princeton University Press.

ESRB High-Level Task Force on Safe Assets (2018). Sovereign bond-backed securities: A feasibility study. European Systemic Risk Board.

Froot, K. and J. Stein (1998). Risk management, capital budgeting and capital structure policy for financial institutions: An integrated approach. Journal of Financial Economics 47, 55-82.

Gao, P., P. Schultz, and Z. Song (2017). Liquidity in a market for unique assets: Specified pool and to-be-announced trading in the mortgage-backed securities market. The Journal of Finance 72(3), 1119-1170.

Garbade, K. (1999). Fixed income analytics. MIT Press, Cambridge MA. 
Gibson, H. D., S. G. Hall, and G. S. Tavlas (2017). A suggestion for constructing a large time-varying conditional covariance matrix. Economics Letters 156(Supplement C), 110 - 113.

Glosten, L. R. and P. R. Milgrom (1985). Bid, ask and transaction prices in a specialist market with heterogeneously informed traders. Journal of Financial Economics 14, 71-100.

Hagströmer, B., R. Henricsson, and L. L. Nordén (2016). Components of the bid-ask spread and variance: A unified approach. Journal of Futures Markets 36(6), 545-563.

Ho, T. and H. R. Stoll (1981). Optimal dealer pricing under transactions and return uncertainty. Journal of Financial Economics 9, 47-73.

Ho, T. and H. R. Stoll (1983). The dynamics of dealer markets under competition. Journal of Finance 38, 1053-1074.

Huang, R. D. and H. R. Stoll (1997). The components of the bid-ask spread: A general approach. Review of Financial Studies 10(4), 995-1034.

Koutmos, G. and A. Pericli (2000). Are multiple hedging instruments better than one? Journal of Portfolio Management. 26(2), 63-70.

Lien, D. and Y. K. Tse (2011). Some recent developments in futures hedging. Journal of Economic Surveys. 16(3), 359-396.

Lucas, A., B. Schwaab, and X. Zhang (2017). Modelling financial sector tail risk in the euro area. Journal of Applied Econometrics 32, 171-191.

Marcus, A. J. and E. Ors (1996). Hedging corporate bond portfolios across the business cycle. Journal of Fixed Income. 4(4), 56-60.

Morgan, L. (2008). Combination hedges applied to us markets. Financial Analysts Journal. 64, 74-84. 
Naik, N. Y. and P. K. Yadav (2003). Risk management with derivatives by dealers and market quality in government bond markets. Journal of Finance 58(5), 1873-1904.

Schönbucher, P. J. (2003). Credit Derivatives Pricing Models: Models, Pricing and Implementation. London: Wiley.

Stoll, H. R. (1978). The pricing of security dealer services: An empirical study of Nasdaq stocks. Journal of Finance 33(4), 1153-1172.

Stulz, R. (1996). Rethinking risk management. Journal of Applied Corporate Finance 9, 8-24.

Tinic, S. M. and R. R. West (1972). The cost of transacting. Journal of Financial and Quantitative Analysis 7(3), 1707-1727.

Yuan, K. (2005). The liquidity service of benchmark securities. Journal of the European Economic Association 3, 1156-1180. 


\section{Appendix: A - Optimal Hedging}

The optimal hedge ratio is the one that minimises the variance of the hedged portfolio's return. To hedge quantity $Q_{1}$ of an asset using quantities of representative combinations of hedge instruments denoted $Q_{2}, Q_{3}$ and $Q_{4}$ gives the following hedge ratios (where $\rho_{i j}$ is the correlation between returns on assets $\mathrm{i}$ and $\mathrm{j}$, and $\sigma_{i}$ is the standard deviation of returns on asset $\mathrm{i}$ ).

One hedge instrument: $\frac{Q_{2}}{Q_{1}}=-\frac{\rho_{12} \sigma_{R_{1}} \sigma_{R_{2}}}{\sigma_{R_{2}}^{2}}$.

Two hedge instruments: $\frac{Q_{2}}{Q_{1}}=-\frac{\left(\rho_{12}-\rho_{13} \rho_{23}\right) \sigma_{1} \sigma_{2}}{\left(1-\rho_{23}^{2}\right) \sigma_{2}^{2}}$ and $\frac{Q_{3}}{Q_{1}}=-\frac{\left(\rho_{13}-\rho_{12} \rho_{23}\right) \sigma_{1} \sigma_{3}}{\left(1-\rho_{23}^{2}\right) \sigma_{3}^{2}}$. Three hedge instruments:

$$
\begin{aligned}
\frac{Q_{2}}{Q_{1}} & =-\frac{\left(1-\rho_{34}^{2}\right) \rho_{12}-\left(\rho_{23}-\rho_{24} \rho_{34}\right) \rho_{13}+\left(\rho_{23} \rho_{34}-\rho_{24}\right) \rho_{14}}{\left(1-\rho_{23}^{2}-\rho_{24}^{2}-\rho_{34}^{2}+2 \rho_{23} \rho_{24} \rho_{34}\right) \sigma_{2}} \\
\frac{Q_{3}}{Q_{1}} & =-\frac{\left(1-\rho_{24}^{2}\right) \rho_{13}-\left(\rho_{23}-\rho_{24} \rho_{34}\right) \rho_{12}+\left(\rho_{23} \rho_{24}-\rho_{34}\right) \rho_{14}}{\left(1-\rho_{23}^{2}-\rho_{24}^{2}-\rho_{34}^{2}+2 \rho_{23} \rho_{24} \rho_{34}\right) \sigma_{3}} \\
\frac{Q_{4}}{Q_{1}} & =-\frac{\left(1-\rho_{23}^{2}\right) \rho_{14}-\left(\rho_{34}-\rho_{24} \rho_{23}\right) \rho_{13}+\left(\rho_{23} \rho_{34}-\rho_{24}\right) \rho_{12}}{\left(1-\rho_{23}^{2}-\rho_{24}^{2}-\rho_{34}^{2}+2 \rho_{23} \rho_{24} \rho_{34}\right) \sigma_{4}} .
\end{aligned}
$$

Correlations used in the the above calculations can be derived from dynamic estimates of variances as described in Gibson et al. (2017). For example, since the variance of $(\mathrm{X}+\mathrm{Y})=\operatorname{variance}(\mathrm{X})+\operatorname{Variance}(\mathrm{Y})+2 \operatorname{Covariance}(\mathrm{X}, \mathrm{Y})$ the Covariance can be constructed from a rearrangement of estimates of $\operatorname{variance}(\mathrm{X}+\mathrm{Y})$, variance $(\mathrm{X})$ and $\operatorname{Variance}(\mathrm{Y})$. 


\section{Appendix B - Robustness}

\section{Comparing with Futures as Hedge}

The comparison of hedge effectiveness using SBBS versus BTP and/or Bund futures can be considered by reference to Table 5 . The first notable outcome is that the senior SBBS is better than the Bund future even in the case of hedging German 10-year bond risk. The returns on a portfolio of Bund and an optimal hedge position in Bund futures has a standard deviation of around $67 \%$ and $64 \%$ respectively of the unhedged position in the SDC period and the recovery respectively. The portfolio involving the senior SBBS by comparison has a relative standard deviation of $32 \%$ and $27 \%$ in these periods (the relative $\mathrm{VaR}$ in both periods is also much lower when the SBBS is used to hedge). Interestingly, the BTP future is a better hedge for the Italian bond than any of the SBBS individually but a combination of SBBS achieves similar hedge effectiveness.

Overall, the Bund futures contract is a weaker hedge for most sovereign bond positions compared with SBBS. Where SBBS are ineffective as hedges for smaller sovereigns (such as IE and PT) the futures are also very ineffective. These sovereigns have a lot of idiosyncratic unhedgable risk but their risks are significantly reduced through diversification.

\section{Hedge Effectiveness at Other Maturities}

Table 6 presents a comparison of hedge effectiveness at the 10 year term-tomaturity with those at 5 and 2 years to maturity (for conciseness only the results for hedging with all three SBBS are shown). In the pre-crisis period hedge effectiveness tends to decline as term shortens. The standard deviation of returns on the hedged positions relative to that of the unhedged positions 
(Rows (i)) increases on average from 0.28 at the 10 year term to 0.36 and 0.49 at the 5 and 2 year terms respectively. The relative value-at-risk comparison (Rows (ii)) increase on average less dramatically than the relative standard deviations (from 0.20 to 0.25 and 0.36 respectively). The average increase in these ratios in the pre-crisis period is a reasonably good indication of what happens at the individual sovereign level (the case of Finland is somewhat of an outlier).

The middle segment of Table 6 depicts the hedge effectiveness measures across terms-to-maturity for the period of the Sovereign Debt Crisis. Here it is not so clear that any significant change occurs across the different terms on average but there is more heterogeneity across sovereigns. The average of the ratio of standard deviations of returns on the hedged position relative to the unhedged, shown in the second last row of the table, move from 0.71 to 0.67 and then to 0.72. Relative VaRs also remain quite flat, moving from 0.67 at the 10 year term to 0.68 and 0.73 at the 5 and 2 year terms respectively. The declines in these ratios tend to be more acute for ES, IT and PT. Significant increases occur (particularly for the 2 year term) for BE, DE, FI and NL. The hedge effectiveness results for the Recovery period show similar levels on average of the two main risk ratios between the 5 and 10 year maturities. A slightly sharper rise occurs in these ratios for the 2 year term and this is mainly explained by the FR case and two of the smaller sovereign markets (BE and FI).

\section{Hedge Effectiveness Under Higher Incidence of Extreme}

\section{Losses}

Table 7 compares hedge effectiveness using a t-copula rather than a Gaussian copula to trigger defaults. There is almost no difference for any sovereign (or on average) in the hedge effectiveness measures over the pre-crisis sample. The largest increase in the ratio of risks occurs for the case of GR (showing a 
very minor 4 point rise). For the Sovereign Debt Crisis and Recovery periods, a similar small change is apparent for all sovereign bonds except those of Germany (and Finland for the SDC period). 
TABle 1. Hedge Effectiveness: Pre-Sov-Debt-Crisis

Backlink to page 16,17 .

\begin{tabular}{|c|c|c|c|c|c|c|c|}
\hline \multirow[b]{2}{*}{ Hedge $=$} & \multicolumn{3}{|c|}{$1 \mathrm{SBBS}$} & \multicolumn{3}{|c|}{ 2-SBBS } & \multirow{2}{*}{$\begin{array}{c}\text { 3-SBBS } \\
\text { Snr-Mezz-Jnr }\end{array}$} \\
\hline & Snr & Mezz & Jnr & Snr-Mezz & Snr-Jnr & Mezz-Jnr & \\
\hline $\mathrm{AT}(\mathrm{i})$ & 0.38 & 0.39 & 0.65 & 0.33 & 0.30 & 0.50 & 0.28 \\
\hline $\operatorname{AT}(\mathrm{ii})$ & 0.27 & 0.28 & 0.65 & 0.23 & 0.18 & 0.43 & 0.16 \\
\hline $\mathrm{BE}(\mathrm{i})$ & 0.35 & 0.37 & 0.64 & 0.28 & 0.25 & 0.48 & 0.23 \\
\hline BE(ii) & 0.29 & 0.30 & 0.63 & 0.24 & 0.20 & 0.42 & 0.17 \\
\hline DE(i) & 0.21 & 0.22 & 0.68 & 0.16 & 0.16 & 0.54 & 0.13 \\
\hline DE(ii) & 0.15 & 0.19 & 0.69 & 0.14 & 0.12 & 0.51 & 0.11 \\
\hline $\mathrm{ES}(\mathrm{i})$ & 0.45 & 0.45 & 0.64 & 0.38 & 0.34 & 0.47 & 0.31 \\
\hline ES(ii) & 0.38 & 0.39 & 0.64 & 0.31 & 0.27 & 0.42 & 0.25 \\
\hline $\mathrm{FI}(\mathrm{i})$ & 0.30 & 0.31 & 0.65 & 0.28 & 0.25 & 0.54 & 0.24 \\
\hline FI(ii) & 0.21 & 0.23 & 0.64 & 0.19 & 0.16 & 0.47 & 0.16 \\
\hline FR(i) & 0.28 & 0.29 & 0.63 & 0.22 & 0.20 & 0.47 & 0.17 \\
\hline FR(ii) & 0.24 & 0.25 & 0.63 & 0.19 & 0.16 & 0.41 & 0.12 \\
\hline GR(i) & 0.64 & 0.67 & 0.73 & 0.54 & 0.49 & 0.51 & 0.45 \\
\hline GR(ii) & 0.54 & 0.56 & 0.67 & 0.40 & 0.40 & 0.42 & 0.33 \\
\hline IE(i) & 0.58 & 0.60 & 0.74 & 0.53 & 0.49 & 0.61 & 0.48 \\
\hline IE(ii) & 0.34 & 0.38 & 0.67 & 0.30 & 0.28 & 0.48 & 0.28 \\
\hline IT(i) & 0.50 & 0.53 & 0.65 & 0.37 & 0.35 & 0.41 & 0.28 \\
\hline IT(ii) & 0.44 & 0.50 & 0.63 & 0.31 & 0.30 & 0.36 & 0.23 \\
\hline $\mathrm{NL}(\mathrm{i})$ & 0.31 & 0.32 & 0.63 & 0.25 & 0.22 & 0.46 & 0.19 \\
\hline NL(ii) & 0.23 & 0.25 & 0.64 & 0.20 & 0.17 & 0.42 & 0.14 \\
\hline $\mathrm{PT}(\mathrm{i})$ & 0.50 & 0.52 & 0.66 & 0.41 & 0.37 & 0.46 & 0.33 \\
\hline PT(ii) & 0.38 & 0.40 & 0.62 & 0.31 & 0.27 & 0.39 & 0.23 \\
\hline
\end{tabular}

Note: Rows(i) contain the ratio of the standard deviation of the hedged returns relative to the unhedged. Rows(ii) contain the average of the ratio of the 95th and 5 th quantiles of the distributions of the hedged returns relative to the unhedged returns. 
TABle 2. Hedge Effectiveness Sov-Debt-Crisis Backlink to page 17 .

\begin{tabular}{|c|c|c|c|c|c|c|c|}
\hline Hedge $=$ & Snr & $\begin{array}{l}1 \mathrm{SBBS} \\
\text { Mezz }\end{array}$ & Jnr & Snr-Mezz & $\begin{array}{l}\text { 2-SBBS } \\
\text { Snr-Jnr }\end{array}$ & Mezz-Jnr & $\begin{array}{c}\text { 3-SBBS } \\
\text { Snr-Mezz-Jnr }\end{array}$ \\
\hline $\operatorname{AT}(\mathrm{i})$ & 0.76 & 0.89 & 1.00 & 0.68 & 0.84 & 1.04 & 0.74 \\
\hline AT(ii) & 0.68 & 0.81 & 0.98 & 0.59 & 0.61 & 0.95 & 0.59 \\
\hline $\mathrm{BE}(\mathrm{i})$ & 0.97 & 0.96 & 0.98 & 0.73 & 1.10 & 0.84 & 0.80 \\
\hline BE(ii) & 0.98 & 0.98 & 1.00 & 0.73 & 0.90 & 0.83 & 0.71 \\
\hline $\mathrm{DE}(\mathrm{i})$ & 0.32 & 1.00 & 1.07 & 0.28 & 0.33 & 1.04 & 0.29 \\
\hline DE(ii) & 0.31 & 1.04 & 1.05 & 0.27 & 0.31 & 0.95 & 0.27 \\
\hline ES(i) & 1.01 & 1.10 & 1.01 & 0.67 & 1.10 & 0.69 & 0.72 \\
\hline ES(ii) & 0.97 & 1.15 & 1.05 & 0.71 & 0.87 & 0.66 & 0.65 \\
\hline $\mathrm{FI}(\mathrm{i})$ & 0.48 & 0.93 & 1.03 & 0.48 & 0.51 & 1.06 & 0.53 \\
\hline FI(ii) & 0.46 & 0.96 & 1.02 & 0.46 & 0.46 & 1.04 & 0.45 \\
\hline $\mathrm{FR}(\mathrm{i})$ & 0.77 & 0.88 & 1.00 & 0.65 & 0.85 & 1 & 0.69 \\
\hline FR(ii) & 0.70 & 0.88 & 1.02 & 0.62 & 0.68 & 1.02 & 0.62 \\
\hline GR(i) & 1.00 & 1.01 & 1.00 & 1.00 & 0.85 & 0.85 & 0.83 \\
\hline GR(ii) & 0.96 & 1.13 & 1.11 & 1.02 & 1.26 & 1.28 & 1.23 \\
\hline $\operatorname{IE}(\mathrm{i})$ & 1.02 & 1.07 & 1.02 & 0.97 & 1.01 & 0.98 & 1.01 \\
\hline IE(ii) & 0.99 & 1.06 & 1.03 & 0.95 & 0.92 & 0.93 & 0.94 \\
\hline $\mathrm{IT}(\mathrm{i})$ & 1.00 & 1.10 & 1.01 & 0.56 & 1.18 & 0.61 & 0.63 \\
\hline IT(ii) & 1.02 & 1.13 & 1.03 & 0.60 & 0.91 & 0.57 & 0.56 \\
\hline NL(i) & 0.51 & 0.91 & 1.02 & 0.52 & 0.54 & 1.07 & 0.57 \\
\hline NL(ii) & 0.47 & 0.94 & 1.05 & 0.48 & 0.48 & 1.03 & 0.49 \\
\hline $\mathrm{PT}(\mathrm{i})$ & 1.01 & 1.05 & 1.01 & 0.99 & 1.01 & 0.98 & 1.00 \\
\hline PT(ii) & 1.01 & 1.02 & 1.01 & 0.95 & 0.90 & 0.92 & 0.91 \\
\hline
\end{tabular}

Note: Rows(i) contain the ratio of the standard deviation of the hedged returns relative to the unhedged. Rows(ii) contain the average of the ratio of the 95th and 5 th quantiles of the distributions of the hedged returns relative to the unhedged returns. 
Table 3. Hedge Effectiveness Post-Sov-Debt-Crisis Backlink to page 16, 18.

\begin{tabular}{|c|c|c|c|c|c|c|c|}
\hline \multirow[b]{2}{*}{ Hedge $=$} & \multicolumn{3}{|c|}{$1 \mathrm{SBBS}$} & \multicolumn{3}{|c|}{ 2-SBBS } & \multirow{2}{*}{$\begin{array}{c}\text { 3-SBBS } \\
\text { Snr-Mezz-Jnr }\end{array}$} \\
\hline & Snr & Mezz & Jnr & Snr-Mezz & Snr-Jnr & Mezz-Jnr & \\
\hline AT(i) & 0.55 & 0.78 & 1.00 & 0.53 & 0.51 & 0.90 & 0.51 \\
\hline AT(ii) & 0.49 & 0.75 & 1.00 & 0.47 & 0.43 & 0.86 & 0.44 \\
\hline $\mathrm{BE}(\mathrm{i})$ & 0.56 & 0.74 & 0.98 & 0.52 & 0.47 & 0.87 & 0.48 \\
\hline BE(ii) & 0.50 & 0.72 & 0.97 & 0.47 & 0.43 & 0.85 & 0.43 \\
\hline DE(i) & 0.27 & 0.87 & 1.04 & 0.26 & 0.27 & 0.92 & 0.25 \\
\hline DE(ii) & 0.28 & 0.90 & 1.04 & 0.27 & 0.27 & 0.93 & 0.26 \\
\hline $\mathrm{ES}(\mathrm{i})$ & 0.98 & 1.02 & 0.97 & 0.68 & 0.74 & 0.58 & 0.57 \\
\hline ES(ii) & 0.96 & 0.94 & 0.96 & 0.71 & 0.72 & 0.59 & 0.57 \\
\hline FI(i) & 0.48 & 0.84 & 1.01 & 0.47 & 0.45 & 0.91 & 0.45 \\
\hline FI(ii) & 0.41 & 0.82 & 1.01 & 0.40 & 0.38 & 0.89 & 0.38 \\
\hline $\mathrm{FR}(\mathrm{i})$ & 0.50 & 0.73 & 0.98 & 0.45 & 0.42 & 0.85 & 0.41 \\
\hline FR(ii) & 0.46 & 0.72 & 0.98 & 0.44 & 0.39 & 0.84 & 0.39 \\
\hline GR(i) & 1.00 & 1.07 & 1.07 & 0.92 & 0.92 & 1.02 & 0.92 \\
\hline GR(ii) & 1.05 & 1.06 & 1.08 & 1.03 & 1.11 & 1.17 & 1.12 \\
\hline IE(i) & 0.90 & 0.89 & 0.97 & 0.79 & 0.78 & 0.81 & 0.73 \\
\hline IE(ii) & 0.86 & 0.83 & 0.95 & 0.71 & 0.72 & 0.77 & 0.65 \\
\hline IT(i) & 0.97 & 1.01 & 0.96 & 0.59 & 0.72 & 0.50 & 0.47 \\
\hline IT(ii) & 0.93 & 0.95 & 0.96 & 0.59 & 0.66 & 0.48 & 0.46 \\
\hline NL(i) & 0.47 & 0.82 & 1.01 & 0.46 & 0.44 & 0.91 & 0.44 \\
\hline NL(ii) & 0.40 & 0.82 & 1.00 & 0.39 & 0.36 & 0.89 & 0.35 \\
\hline $\mathrm{PT}(\mathrm{i})$ & 1.00 & 1.02 & 1.00 & 0.87 & 0.85 & 0.79 & 0.79 \\
\hline PT(ii) & 0.99 & 1.02 & 1.00 & 0.87 & 0.83 & 0.75 & 0.74 \\
\hline
\end{tabular}

Note: Rows(i) contain the ratio of the standard deviation of the hedged returns relative to the unhedged. Rows(ii) contain the average of the ratio of the 95th and 5 th quantiles of the distributions of the hedged returns relative to the unhedged returns. 
TABLE 4. Diversification and Hedge Effectiveness Backlink to page 19.

\begin{tabular}{|c|c|c|c|c|c|c|}
\hline \multirow[b]{2}{*}{ Weighting $=$} & \multicolumn{2}{|c|}{ Pre-Crisis } & \multicolumn{2}{|c|}{ Sov Debt Crisis } & \multicolumn{2}{|c|}{ RECOVERY } \\
\hline & Equal & Size & Equal & Size & Equal & Size \\
\hline \multicolumn{7}{|l|}{ 10-Year } \\
\hline EA $($ Hedged $) /$ EA (i) & 0.32 & 0.29 & 1 & 0.97 & 0.88 & 0.76 \\
\hline EA(Hedged)/EA (ii) & 0.27 & 0.26 & 0.96 & 0.93 & 0.82 & 0.69 \\
\hline EA(Hedged)/DE (i) & 0.29 & 0.27 & 1.08 & 0.99 & 0.96 & 0.76 \\
\hline EA(Hedged)/DE (ii) & 0.24 & 0.24 & 0.98 & 0.86 & 0.89 & 0.71 \\
\hline \multicolumn{7}{|l|}{ 5-Year } \\
\hline EA(Hedged)/EA (i) & 0.53 & 0.57 & 1.01 & 0.99 & 0.83 & 0.85 \\
\hline EA(Hedged)/EA (ii) & 0.54 & 0.56 & 1 & 1.01 & 0.8 & 0.79 \\
\hline EA(Hedged)/DE (i) & 0.5 & 0.54 & 1.52 & 1.25 & 0.79 & 0.97 \\
\hline EA(Hedged)/DE (ii) & 0.5 & 0.54 & 1.34 & 1.12 & 0.73 & 0.9 \\
\hline \multicolumn{7}{|l|}{ 2-Year } \\
\hline EA(Hedged)/EA (i) & 0.38 & 0.36 & 1.01 & 0.99 & 0.95 & 0.95 \\
\hline EA(Hedged)/EA (ii) & 0.31 & 0.28 & 1.01 & 1.04 & 0.93 & 0.9 \\
\hline EA(Hedged)/DE (i) & 0.3 & 0.33 & 3.52 & 1.81 & 1.21 & 1.47 \\
\hline EA(Hedged)/DE (ii) & 0.24 & 0.26 & 2.86 & 1.64 & 1.15 & 1.38 \\
\hline
\end{tabular}

Note: Rows(i) contain the ratio of the standard deviation of returns on the portfolio of EA sovereigns (where the components are hedged) relative to the unhedged (or German). Rows(ii) contain the average of the ratio of the 95th and 5th quantiles of the distributions of the hedged returns relative to the unhedged (or German) returns. The hedge used in all cases is the Senior SBBS. The main focus of this table is a comparison of hedged relative to unhedged risks after diversification. In each case the returns on the portfolio of sovereigns is calculated assuming (a) an Equal weighting of components and (b) a Market-Size based weighting of components. The rounded weights for the size-weighting are: Austria (3\%), Belgium (5\%), Finland (1\%), France (23\%), Germany (17\%), Greece (1\%), Ireland (2\%), Italy (27\%), Netherlands(5\%), Portugal (2\%), and Spain (13\%). 
TABle 5. Futures-Based Hedge Effectiveness SDC and Recovery Backlink to page 30 .

\begin{tabular}{|c|c|c|c|c|c|c|}
\hline \multirow[b]{2}{*}{ Hedge $=$} & \multicolumn{3}{|c|}{ Sov Debt Crisis } & \multicolumn{3}{|c|}{ RECOVERY } \\
\hline & BUND & BTP & BUND+BTP & BUND & BTP & BUND+BTP \\
\hline $\operatorname{AT}(\mathrm{i})$ & 0.72 & 1.07 & 0.73 & 0.83 & 0.97 & 0.81 \\
\hline AT(ii) & 0.74 & 1.13 & 0.76 & 0.77 & 0.93 & 0.71 \\
\hline $\mathrm{BE}(\mathrm{i})$ & 0.99 & 0.89 & 0.81 & 0.90 & 0.94 & 0.84 \\
\hline $\mathrm{BE}(\mathrm{ii})$ & 1.10 & 1.02 & 0.88 & 0.84 & 0.95 & 0.78 \\
\hline $\mathrm{DE}(\mathrm{i})$ & 0.67 & 1.03 & 0.67 & 0.64 & 0.97 & 0.65 \\
\hline $\mathrm{DE}(\mathrm{ii})$ & 0.68 & 1.06 & 0.68 & 0.56 & 0.96 & 0.56 \\
\hline $\mathrm{ES}(\mathrm{i})$ & 1.02 & 0.64 & 0.67 & 0.98 & 0.76 & 0.77 \\
\hline $\mathrm{ES}(\mathrm{ii})$ & 0.98 & 0.67 & 0.65 & 0.96 & 0.74 & 0.74 \\
\hline $\mathrm{FI}(\mathrm{i})$ & 0.66 & 1.05 & 0.67 & 0.68 & 0.97 & 0.68 \\
\hline $\mathrm{FI}(\mathrm{ii})$ & 0.62 & 1.00 & 0.62 & 0.59 & 0.93 & 0.56 \\
\hline $\mathrm{FR}(\mathrm{i})$ & 0.78 & 1.06 & 0.79 & 0.84 & 0.96 & 0.81 \\
\hline FR(ii) & 0.82 & 1.12 & 0.78 & 0.80 & 0.92 & 0.73 \\
\hline GR(i) & 1.03 & 1.13 & 1.17 & 1.00 & 1.00 & 1.00 \\
\hline GR(ii) & 1.03 & 1.18 & 1.19 & 1.03 & 1.00 & 1.02 \\
\hline IE(i) & 1.00 & 0.95 & 0.94 & 0.99 & 1.00 & 0.99 \\
\hline IE(ii) & 0.96 & 0.98 & 0.95 & 0.96 & 0.99 & 0.97 \\
\hline IT(i) & 1.03 & 0.48 & 0.51 & 0.97 & 0.54 & 0.55 \\
\hline IT(ii) & 1.07 & 0.43 & 0.41 & 0.95 & 0.41 & 0.42 \\
\hline NL(i) & 0.67 & 1.05 & 0.68 & 0.71 & 0.98 & 0.71 \\
\hline NL(ii) & 0.71 & 1.03 & 0.69 & 0.63 & 0.97 & 0.62 \\
\hline $\mathrm{PT}(\mathrm{i})$ & 1.00 & 0.96 & 0.95 & 1.00 & 0.97 & 0.98 \\
\hline $\mathrm{PT}(\mathrm{ii})$ & 1.03 & 0.92 & 0.95 & 1.01 & 0.95 & 0.94 \\
\hline
\end{tabular}

Note: Rows(i) contain the ratio of the standard deviation of the hedged returns relative to the unhedged. Rows(ii) contain the average of the ratio of the 95th and 5th quantiles of the distributions of the hedged returns relative to the unhedged returns. 
TABle 6. Hedge Effectiveness: 10, 5 \& 2 Year Terms-to-Maturity Backlink to page 30 .

\begin{tabular}{|c|c|c|c|c|c|c|c|c|c|}
\hline \multirow[b]{2}{*}{ Term $=$} & \multicolumn{3}{|c|}{ Pre-Crisis } & \multicolumn{3}{|c|}{ Sov Debt Crisis } & \multicolumn{3}{|c|}{ RECOVERY } \\
\hline & 10 Year & 5 Year & 2 Year & 10 Year & 5 Year & 2 Year & 10 Year & 5 Year & 2 Year \\
\hline $\operatorname{AT}(\mathrm{i})$ & 0.28 & 0.35 & 0.53 & 0.74 & 0.71 & 0.77 & 0.51 & 0.56 & 0.76 \\
\hline AT(ii) & 0.16 & 0.20 & 0.42 & 0.59 & 0.60 & 0.70 & 0.44 & 0.49 & 0.76 \\
\hline $\mathrm{BE}(\mathrm{i})$ & 0.23 & 0.33 & 0.44 & 0.80 & 0.77 & 0.85 & 0.48 & 0.65 & 0.85 \\
\hline $\mathrm{BE}(\mathrm{ii})$ & 0.17 & 0.19 & 0.24 & 0.71 & 0.74 & 0.80 & 0.43 & 0.55 & 0.90 \\
\hline $\mathrm{DE}(\mathrm{i})$ & 0.13 & 0.15 & 0.25 & 0.29 & 0.31 & 0.52 & 0.25 & 0.28 & 0.32 \\
\hline $\mathrm{DE}$ (ii) & 0.11 & 0.12 & 0.18 & 0.27 & 0.31 & 0.45 & 0.26 & 0.27 & 0.33 \\
\hline $\mathrm{ES}(\mathrm{i})$ & 0.31 & 0.33 & 0.38 & 0.72 & 0.56 & 0.58 & 0.57 & 0.50 & 0.57 \\
\hline ES(ii) & 0.25 & 0.20 & 0.23 & 0.65 & 0.62 & 0.64 & 0.57 & 0.52 & 0.63 \\
\hline FI(i) & 0.24 & 0.45 & 0.74 & 0.53 & 0.55 & 0.80 & 0.45 & 0.59 & 0.73 \\
\hline FI(ii) & 0.16 & 0.20 & 0.70 & 0.45 & 0.44 & 0.74 & 0.38 & 0.44 & 0.76 \\
\hline $\mathrm{FR}(\mathrm{i})$ & 0.17 & 0.19 & 0.25 & 0.69 & 0.67 & 0.71 & 0.41 & 0.51 & 0.69 \\
\hline FR(ii) & 0.12 & 0.14 & 0.18 & 0.62 & 0.62 & 0.65 & 0.39 & 0.48 & 0.73 \\
\hline GR(i) & 0.45 & 0.55 & 0.66 & 0.83 & 1.00 & 1.01 & 0.92 & - & - \\
\hline GR(ii) & 0.33 & 0.40 & 0.39 & 1.23 & 1.31 & 1.42 & 1.12 & - & - \\
\hline $\mathrm{IE}(\mathrm{i})$ & 0.48 & 0.60 & 0.83 & 1.01 & 0.87 & - & 0.73 & 0.86 & - \\
\hline IE(ii) & 0.28 & 0.60 & 0.73 & 0.94 & 0.90 & - & 0.65 & 0.81 & - \\
\hline $\operatorname{IT}(\mathrm{i})$ & 0.28 & 0.36 & 0.41 & 0.63 & 0.41 & 0.38 & 0.47 & 0.46 & 0.40 \\
\hline IT(ii) & 0.23 & 0.30 & 0.27 & 0.56 & 0.49 & 0.39 & 0.46 & 0.45 & 0.43 \\
\hline $\mathrm{NL}(\mathrm{i})$ & 0.19 & 0.29 & 0.46 & 0.57 & 0.58 & 0.75 & 0.44 & 0.53 & 0.61 \\
\hline NL(ii) & 0.14 & 0.16 & 0.28 & 0.49 & 0.47 & 0.58 & 0.35 & 0.43 & 0.64 \\
\hline $\mathrm{PT}(\mathrm{i})$ & 0.33 & 0.41 & 0.42 & 1.00 & 0.91 & 0.83 & 0.79 & 0.87 & 0.92 \\
\hline PT(ii) & 0.23 & 0.24 & 0.31 & 0.91 & 0.95 & 0.97 & 0.74 & 0.89 & 1.01 \\
\hline $\operatorname{Avg}(i)$ & 0.28 & 0.36 & 0.49 & 0.71 & 0.67 & 0.72 & 0.55 & 0.58 & 0.65 \\
\hline Avg(ii) & 0.20 & 0.25 & 0.36 & 0.67 & 0.68 & 0.73 & 0.53 & 0.53 & 0.69 \\
\hline
\end{tabular}

Note: Rows(i) contain the ratio of the standard deviation of the hedged returns relative to the unhedged. Rows(ii) contain the average of the ratio of the 95th and 5th quantiles of the distributions of the hedged returns relative to the unhedged returns. The hedge used in all cases involves all three SBBS (Senior, Mezzanine and Junior). Missing cells (for IE and GR) are due to inactive markets at specific terms-to-maturity during the Sovereign Debt Crisis and Recovery periods. 
TABLE 7. Hedge Effectiveness: Gaussian versus T-Copula Default Trigger

Backlink to page 31 .

\begin{tabular}{|c|c|c|c|c|c|c|}
\hline & \multicolumn{2}{|c|}{ Pre-Crisis } & \multicolumn{2}{|c|}{ Sov Debt Crisis } & \multicolumn{2}{|c|}{ RECOVERY } \\
\hline & Gaussian & T-Dist & Gaussian & T-Dist & Gaussian & T-Dist \\
\hline $\mathrm{AT}(\mathrm{i})$ & 0.28 & 0.28 & 0.74 & 0.76 & 0.51 & 0.54 \\
\hline $\mathrm{AT}(\mathrm{ii})$ & 0.16 & 0.17 & 0.59 & 0.62 & 0.44 & 0.48 \\
\hline $\mathrm{BE}(\mathrm{i})$ & 0.23 & 0.23 & 0.8 & 0.81 & 0.48 & 0.51 \\
\hline $\mathrm{BE}(\mathrm{ii})$ & 0.17 & 0.18 & 0.71 & 0.74 & 0.43 & 0.46 \\
\hline $\mathrm{DE}(\mathrm{i})$ & 0.13 & 0.19 & 0.29 & 0.55 & 0.25 & 0.44 \\
\hline $\mathrm{DE}(\mathrm{ii})$ & 0.11 & 0.17 & 0.27 & 0.52 & 0.26 & 0.47 \\
\hline $\mathrm{ES}(\mathrm{i})$ & 0.31 & 0.32 & 0.72 & 0.66 & 0.57 & 0.6 \\
\hline $\mathrm{ES}(\mathrm{ii})$ & 0.25 & 0.24 & 0.65 & 0.62 & 0.57 & 0.6 \\
\hline $\mathrm{FI}(\mathrm{i})$ & 0.24 & 0.25 & 0.53 & 0.62 & 0.45 & 0.52 \\
\hline FI(ii) & 0.16 & 0.17 & 0.45 & 0.56 & 0.38 & 0.45 \\
\hline $\mathrm{FR}(\mathrm{i})$ & 0.17 & 0.16 & 0.69 & 0.74 & 0.41 & 0.43 \\
\hline FR(ii) & 0.12 & 0.12 & 0.62 & 0.56 & 0.39 & 0.41 \\
\hline GR(i) & 0.45 & 0.49 & 0.83 & 0.83 & 0.92 & 1 \\
\hline GR(ii) & 0.33 & 0.37 & 1.23 & 1.29 & 1.12 & 1.27 \\
\hline $\operatorname{IE}(\mathrm{i})$ & 0.48 & 0.5 & 1.01 & 1 & 0.73 & 0.74 \\
\hline IE(ii) & 0.28 & 0.27 & 0.94 & 0.91 & 0.65 & 0.66 \\
\hline $\operatorname{IT}(\mathrm{i})$ & 0.28 & 0.3 & 0.63 & 0.6 & 0.47 & 0.49 \\
\hline IT(ii) & 0.23 & 0.29 & 0.56 & 0.6 & 0.46 & 0.45 \\
\hline NL(i) & 0.19 & 0.19 & 0.57 & 0.63 & 0.44 & 0.49 \\
\hline NL(ii) & 0.14 & 0.13 & 0.49 & 0.54 & 0.35 & 0.43 \\
\hline $\mathrm{PT}(\mathrm{i})$ & 0.33 & 0.35 & 1 & 1.02 & 0.79 & 0.82 \\
\hline PT(ii) & 0.23 & 0.24 & 0.91 & 0.86 & 0.74 & 0.79 \\
\hline $\operatorname{Avg}(i)$ & 0.28 & 0.3 & 0.71 & 0.75 & 0.55 & 0.6 \\
\hline $\operatorname{Avg}($ ii) & 0.2 & 0.21 & 0.67 & 0.71 & 0.53 & 0.59 \\
\hline
\end{tabular}

Note: Rows(i) contain the ratio of the standard deviation of the hedged returns relative to the unhedged. Rows(ii) contain the average of the ratio of the 95th and 5th quantiles of the distributions of the hedged returns relative to the unhedged returns. The hedge used in all cases involves all three SBBS (Senior, Mezzanine and Junior). The main focus of this table is a comparison of hedged relative to unhedged risks when using a T-copula to trigger correlated defaults rather than a Gaussian copula. 
Figure 1. Estimated Yields on SBBS Tranches \& Selected Sovereigns (\%). Backlink to page 14 .

(A) 70:30 SBBS Yields

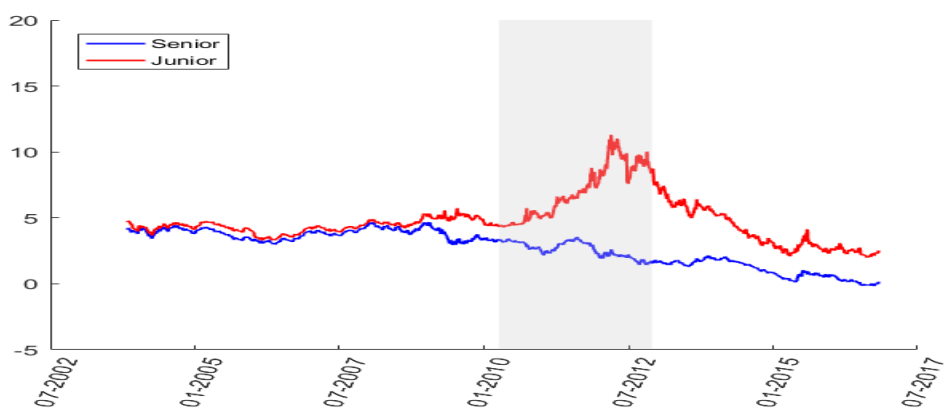

(B) 70:20:10 SBBS Yields

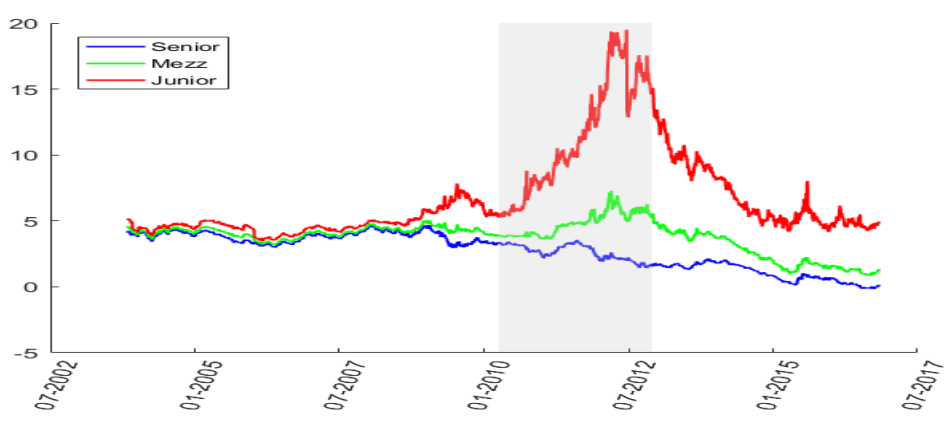

(c) Yields of DE, IT, GR \& PT

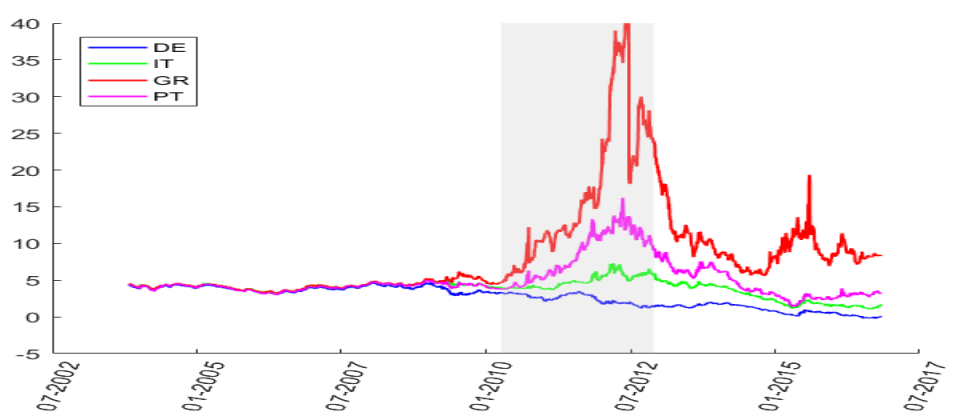

Note: Shaded area is euro area Sovereign Debt Crisis period (November 2009-August 2012). 
Figure 2. Single \& Composite Hedging (DE, FR, NL). Backlink to page 16, 16.

(A) DE: Single Hedge

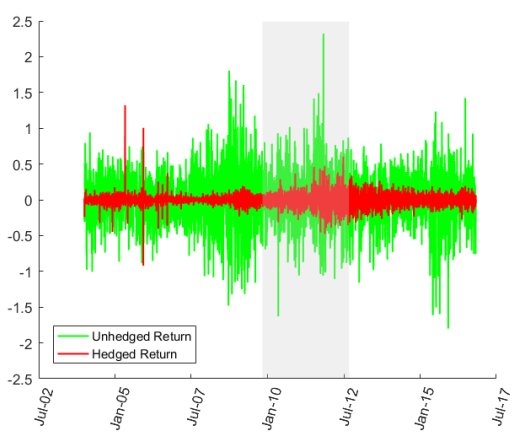

(c) FR: Single Hedge

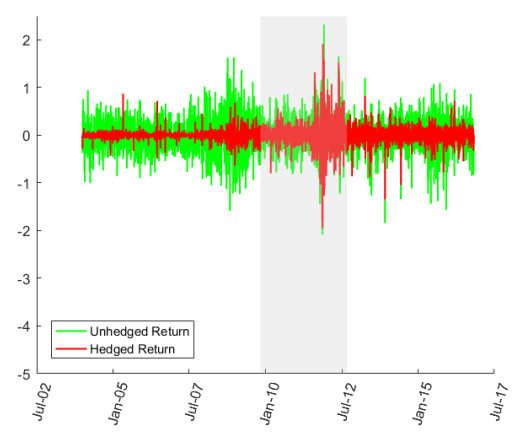

(E) NL: Single Hedge

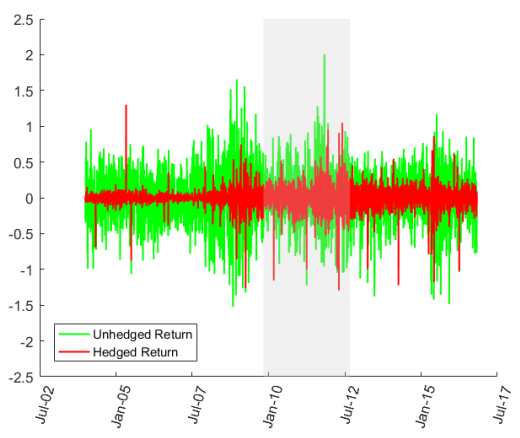

(в) DE: Composite Hedge

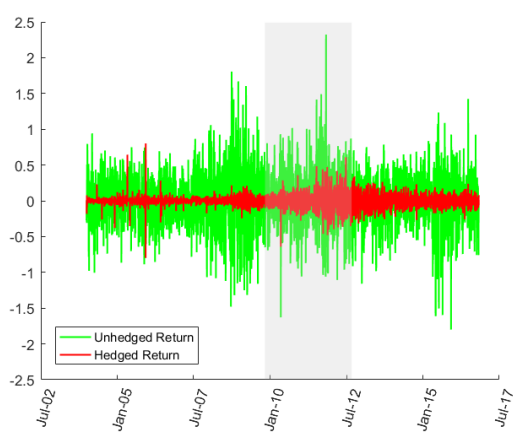

(D) FR: Composite Hedge

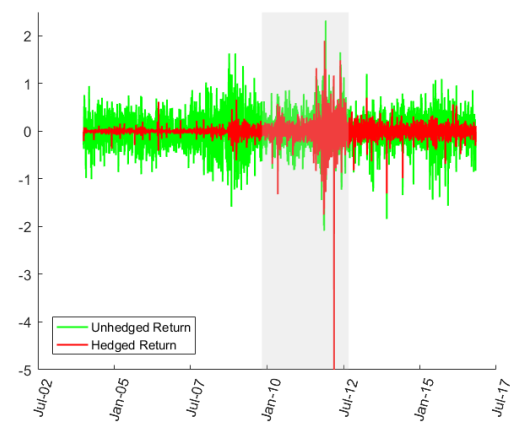

(F) NL: Composite Hedge

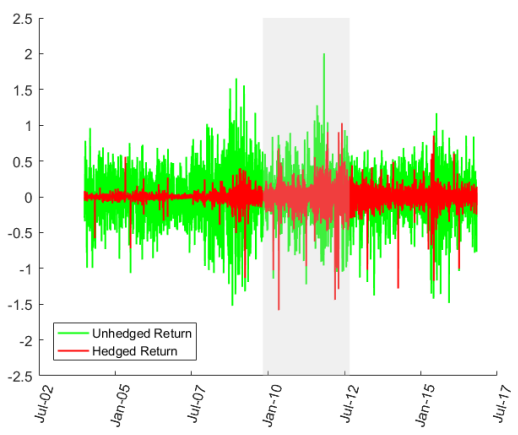

Note: The cases of Austria (AT) and Finland (FI) are not shown above but are quite similar to the case of NL. The single hedge involves just the senior SBBS. The composite hedge involves the senior and mezzanine SBBS. The returns are measured in basis points (left axis). 
Figure 3. Single \& Composite Hedging (BE, ES, IT). Backlink to page 16.

(A) BE: Single Hedge

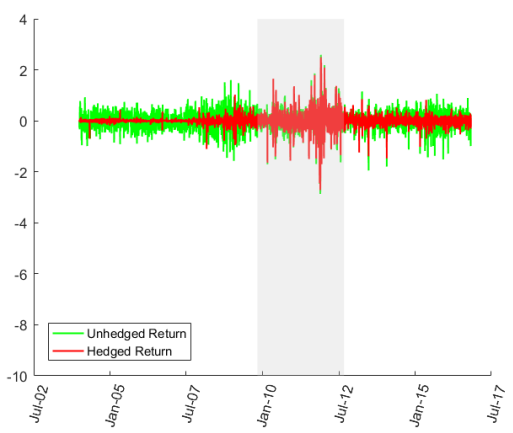

(c) ES: Single Hedge

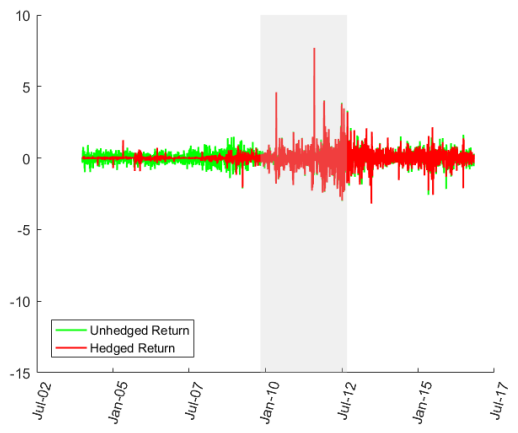

(E) IT: Single Hedge

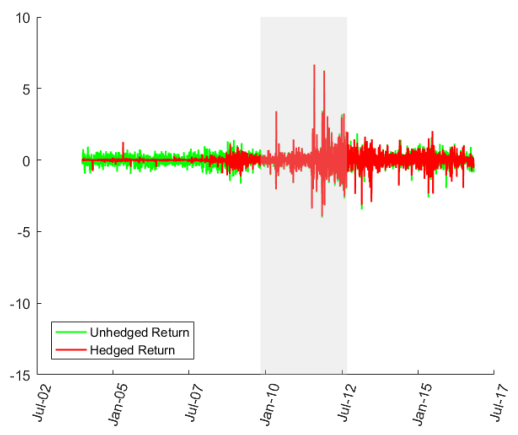

(в) BE: Composite Hedge

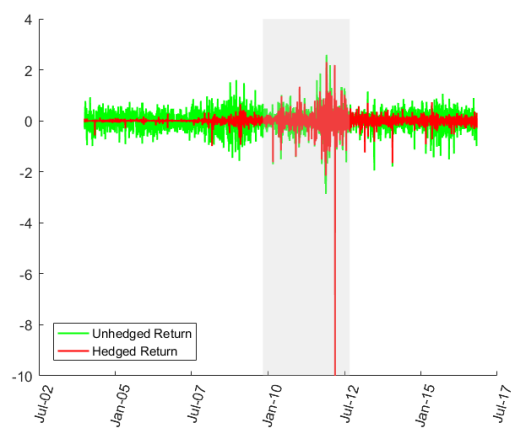

(D) ES: Composite Hedge

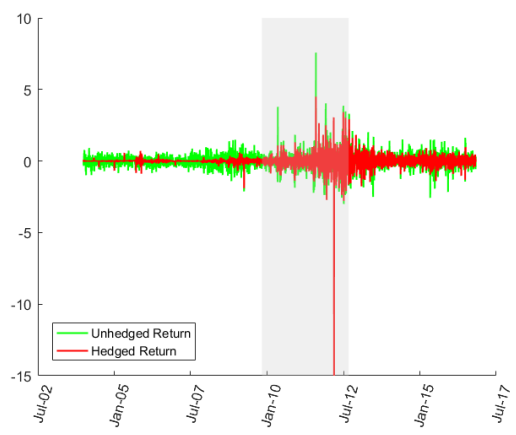

(F) IT: Composite Hedge

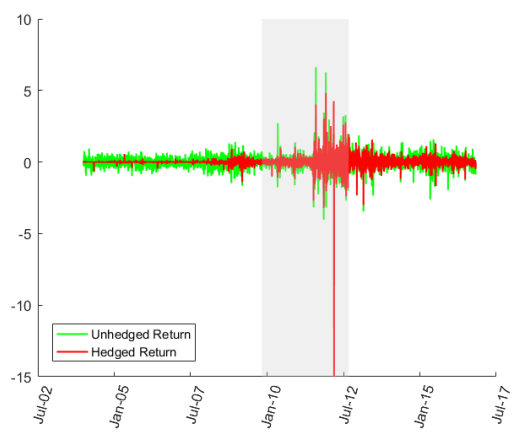

Note: The single hedge involves just the senior SBBS. The composite hedge involves the senior and mezzanine SBBS. The returns are measured in basis points (left axis). 
Figure 4. Single \& Composite Hedging (GR, IE, PT). Backlink to page 17.

(A) GR: Single Hedge

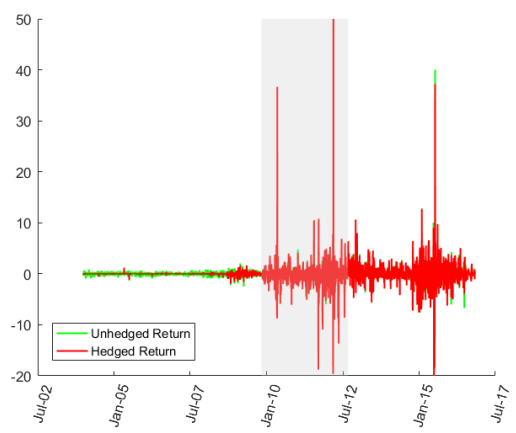

(c) IE: Single Hedge

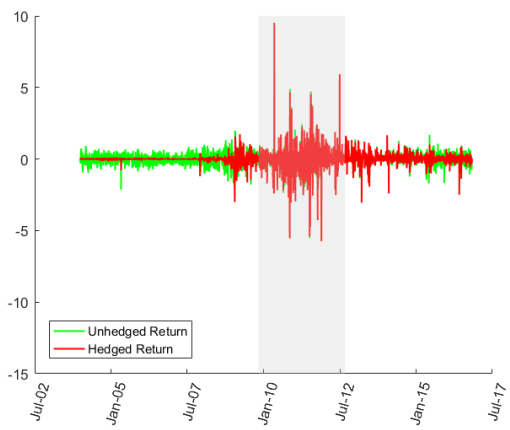

(E) PT: Single Hedge

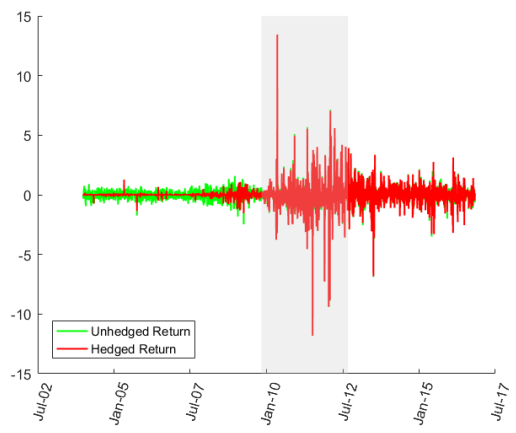

(B) GR: Composite Hedge

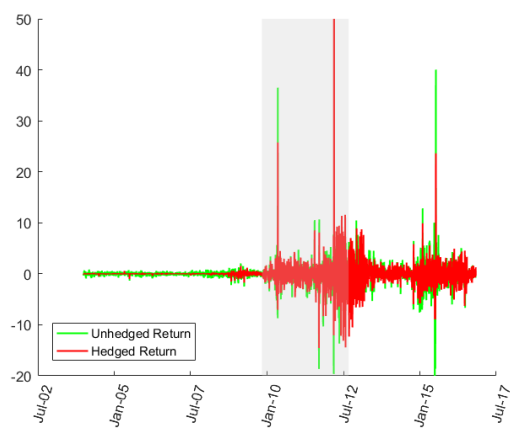

(D) IE: Composite Hedge

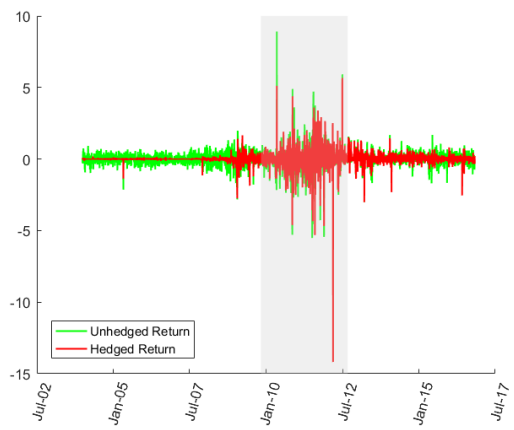

(F) PT: Composite Hedge

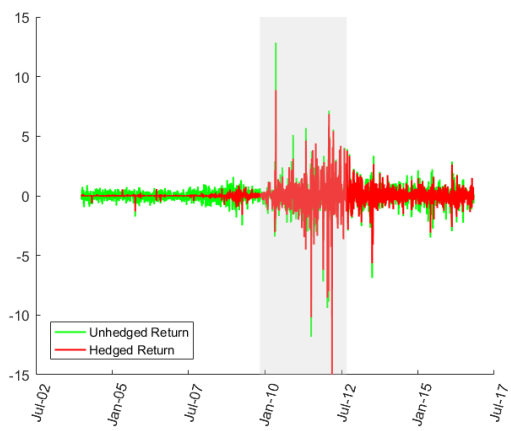

Note: The single hedge involves just the senior SBBS. The composite hedge involves the senior and mezzanine SBBS. The returns are measured in basis points (left axis). 
Figure 5. Portfolio returns with and without hedged components. Backlink to page 18.

(A) Pre-SDC (Hedge=Senior)

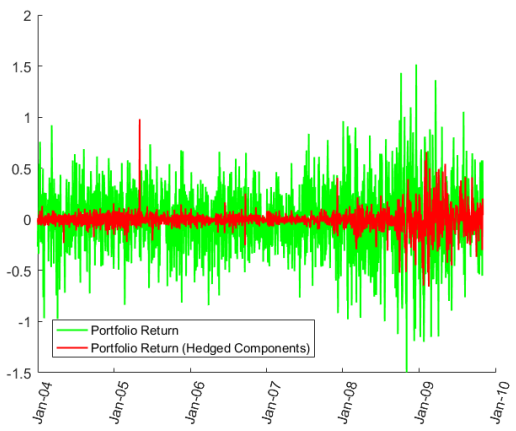

(c) SDC \& Recovery (Hedge=Senior)

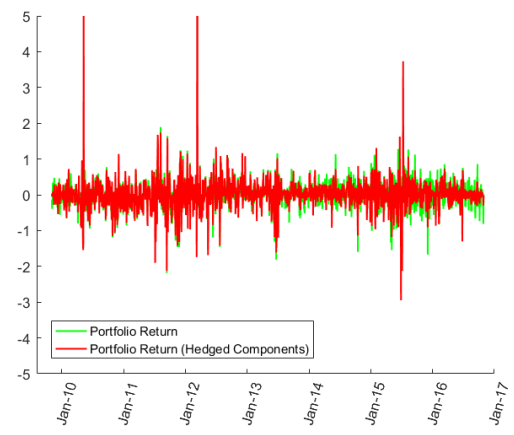

(в) Pre-SDC (Hedge $=$ Snr \& Mezz)

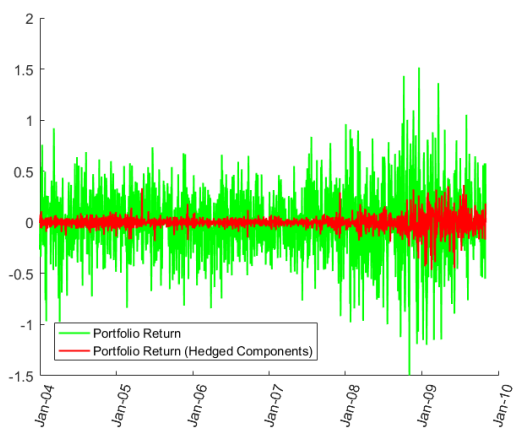

(D) SDC \& Recovery (Hedge=Snr \& Mezz)

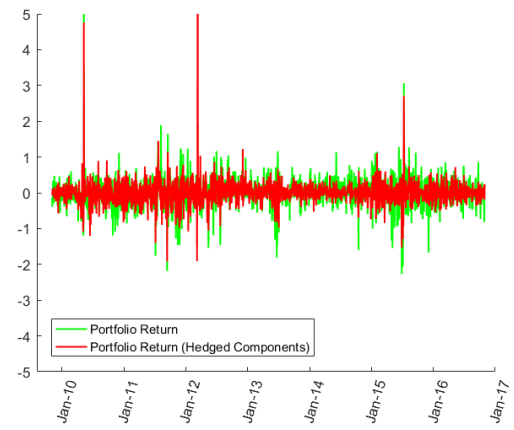

Note: The single hedge involves just the senior SBBS. The composite hedge involves the senior and mezzanine SBBS. The returns are measured in basis points (left axis). 
FiguRE 6. German 10-year returns compared with those from an 11-country portfolio of sovereigns hedged with SBBS. Backlink to page 19.

(A) Pre-SDC

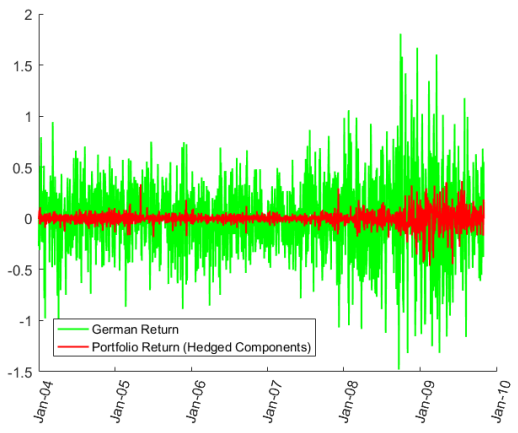

(B) SDC \& Recovery

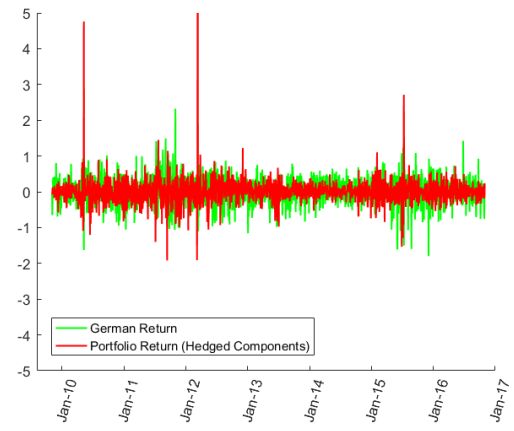

Note: The hedge involves just the senior SBBS. The 10-year yields are utilised. The returns are measured in basis points (left axis). 